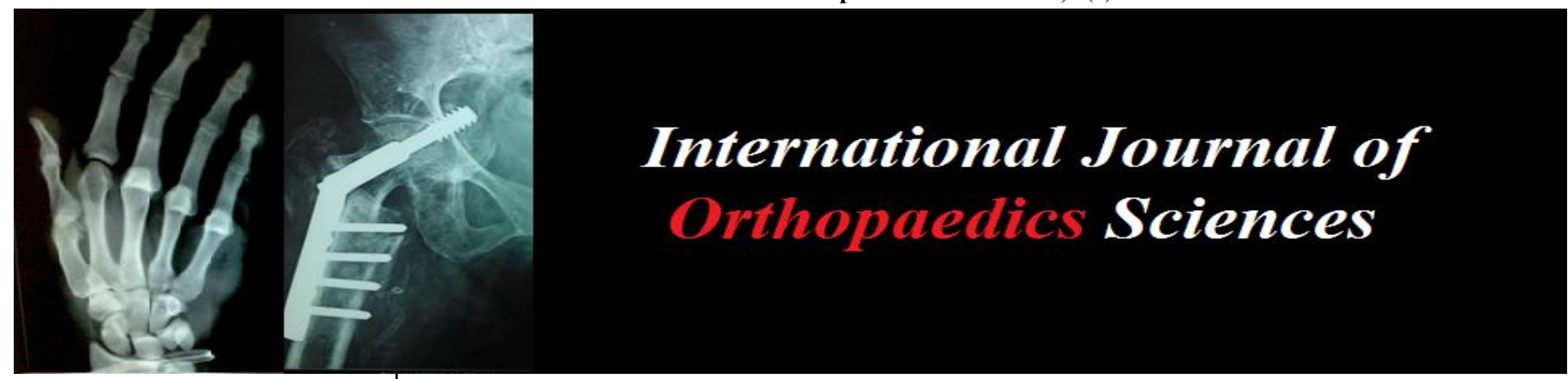

ISSN: $2395-1958$

IJOS 2017; 3(4): 688-692

(C) 2017 IJOS

www.orthopaper.com

Received: 21-08-2017

Accepted: 27-09-2017

Mahendhira varman J

Asst. Professors,

Department of Orthopaedics

SRM Medical College \& RC,

Chennai, India

\section{Rajavel K}

Asst. Professors,

Department of Orthopaedics SRM Medical College \& RC,

Chennai, India

Balaji D

Asst. Professors,

Department of Orthopaedics SRM Medical College \& RC,

Chennai, India
Correspondence

Rajavel K

Asst. Professors,

Department of Orthopaedics

SRM Medical College \& RC,

Chennai, India

\section{Functional outcome following open reconstruction of anterior cruciate ligament using bone patellar tendon bone graft and interference screws}

\author{
Mahendhira varman J, Rajavel K and Balaji D
}

DOI: https://doi.org/10.22271/ortho.2017.v3.i4j.96

\section{Abstract}

Background: Various surgical methods have been described for the anterior cruciate ligament (ACL)tear with its own merits and demerits. Though arthroscopic reconstruction is the commonly done surgery, open reconstruction is still a good alternative in hospitals where scopy instruments/facilities are not available. This studies aim was to analyse the functional outcome following open ACL reconstruction using Bone- patellar tendon -bone graft (BPTB)

Materials and methods: This is a prospective study of 30 patients aged between 18 to 50years with complete ACL tear with or without meniscal injury. Patients were treated by open reconstruction using bone- patellar tendon- bone graft and interference screws. Appropriate post-operative care was given. ACL rehabilitation protocol was followed for all patients. The functional evaluation of the patients was done at 1year follow up. We used IKDC-2000, Lysholm \& Gillquist scoring system for the evaluation of the results.

Results: $90 \%$ of patients had normal or near normal knee, $10 \%$ of the patients had abnormal knee as per IKDC 2000 scoring system. excellent-good results were seen in $83 \%$ of the cases, while $14 \%$ had intermediate grade. The complications observed were anterior knee pain $(26 \%)$, mildnumbness over donor site $(13 \%)$, patella fracture $(n=1)$.

Conclusion: Open ACL reconstruction is still a good alternative to arthroscopic reconstruction in hospitals where scopy instruments/facilities are not available.

Keywords: Anterior cruciate ligament tear, bone- patellar tendon- bone graft(BPTB),Open ACL reconstruction

\section{Introduction}

Anterior cruciate ligament is one of the two cruciate ligaments in the knee joint. The ACL is a complex structure that attaches to the posterolateral aspect of the intercondylar notch and the anteromedial aspect of the central tibial eminence ${ }^{[1,10,11]}$. The length of the ACL is $31-38 \mathrm{~mm}$ and the width is $11 \mathrm{~mm}$, on average ${ }^{[1]}$. Most authors believe that the anteromedial and posterolateral bundles tighten in flexion and extension, respectively ${ }^{[1]}$. The tensile strengthof the ACL has been reported to range from 1725 to 2195 N; (Saperstein and Hershman, 1994). It is responsible for anterior stability, proprioception and prevents hyperextension of knee ${ }^{[10,11]}$ ACL tear is one of the most common the knee ligament injuries. The most common mode of injury is external rotation with abduction of the flexed knee or hyperextension of knee in internal rotation. Classic history of an ACL injury begins with a noncontact deceleration, jumping or cutting action.

Treatment options available include 1. Non operative 2. Primary repair 3. Reconstruction There are many factors to be considered when Deciding whether an ACL rupture should be treated surgically or conservatively. Among these factors are the degree of instability, the presence of meniscal lesions, the patient's level of athletic activity and the patient's age. A widely advocated treatment strategy is to recommend early reconstruction in the highly active patients and to start with a non-surgical treatment for the less active patients. Most commonly done surgery for ACL deficient knee is intra articular reconstruction of ACL with bonepatellar tendon- bone (BPTB) Autograft or Hamstring Autograft.

In 2002, $97 \%$ of surgeons treating professional sportsmen from the American NFL used the 
BPTB graft ${ }^{[2]}$ The use of the hamstrings graft in the elite sports player results in increased rerupture rate on return to sport [3]. Hamstring weakness in flexion and rotation is reported ${ }^{[4]}$. The cause of quadriceps weakness following ACL reconstruction is thought to be related to rehabilitation deficiency rather than donor site ${ }^{[3]}$. Studies have shown no difference in the quadriceps weakness between patients treated with allograft or autograft BPTB grafts ${ }^{[5]}$.

Even now the facility, equipments and Arthroscopy surgeons to do Arthroscopic surgery are not available in Sub urban area, in most of the Govt hospitals in our Country. Hence we decided to conduct a prospective study to find out the functional outcome following open ACL reconstruction done in our institution situated in Tamil Nadu. Our objectives were to 1 .Analyse the functional outcome 2. Find out incidence of common complications. The most widely used knee score for evaluation of ACL injury and reconsruction are the Lysholm and Gillquist, IKDC 2000 scoring systems ${ }^{[6]}$. So we also used the same scoring systems in our study.

\section{Materials and Methods}

This prospective study was conducted from November 2015 to October 2017 in our institution. The study was carried out in accordance with declaration of Helsinki and guidelines for good clinical practice. This study was approved by our Institution's Ethical committee and Review board, and informed consent was obtained from all participating patients. ACL reconstruction was done for 32 patients during our study period, out of which 2 patients defaulted from follow up. Diagnostic criteria was clinically ACL deficient knee confirmed by MRI. Inclusion Criteria were 1.Patients of both sexes between 18-50yrs of age, 2. Associated with/without meniscus injury, 3.New \& old cases. Exclusion Criteria were 1.Associated with fractures around knee 2. Associated with Posterior cruciate ligament injury 3.Associated with collateral ligament injury 4. Patients below $18 \mathrm{yrs} \&$ above $50 \mathrm{yrs}$ of age.

\section{Surgical Technique}

Patient positioned supine on the operating table. Contralateral extremity padded well to avoid pressure on susceptible areas. Tourniquet applied to thigh as proximally as possible. Affected knee examined under the anaesthesia and findings recorded. Scrubbing of knee, thigh and leg was done by using Betadine scrub solution. Draping was done after painting the above mentioned areas. A midline vertical incision measuring about $10-15 \mathrm{~cm}$ is made starting about few $\mathrm{cm}$ above the superior pole of patella. Patella and patellar tendon exposed through the plane of the prepatellar bursa. The width of the patellar tendon was measured. Two parallel incisions through the full thickness of the tendon were made - $10 \mathrm{~mm}$ apart, from inferior pole of the patella to the attachment of the tibial tuberosity if the patellar tendon is at least $30 \mathrm{~mm}$ wide. If the patellar tendon was not this wide, we used only the central third.

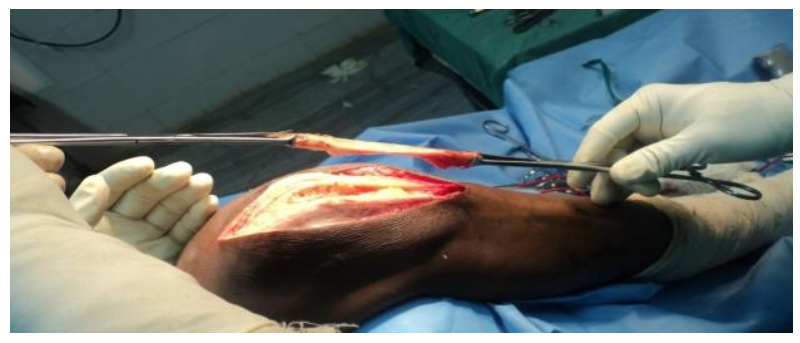

Fig 1: BPTB graft harvested
The parallel incisions were continued through the aponeurosis, over the anterior surface of the patella from its inferior pole to the quadriceps tendon insertion, and distally through the periosteum over the tibial tuberosity, extending 2 to $3 \mathrm{~cm}$ inferior to the tendon insertion. The incisions mark the line for releasing the graft with its patellar and Tibial tuberosity bony attachments. With an oscillating saw, we removed a 2- to 3-cm-long segment of tibial tuberosity bone by sawing along the previously made periosteal incisions, directing the saw from each side of the bone at a 45-degree angle.

After both sides of the tibial tuberosity bone have been sawed, we released the proximal and distal bony extents with a $1-\mathrm{cm}$ osteotome and then "poped up" and freed the graft. Using the oscillating saw along the previously made parallel incisions in the anterior patellar aponeurosis, we made parallel cuts through the outer cortex of the patella from the inferior pole, and released the full thickness of the outer cortex of the patella from inferior to superior. The bone-tendon-bone graft was sized so that it passes snugly but easily through a $10-\mathrm{mm}$ cylindrical sizer. Two drill holes were made through the patellar bone fragment and two through the tibial tuberosity bone.

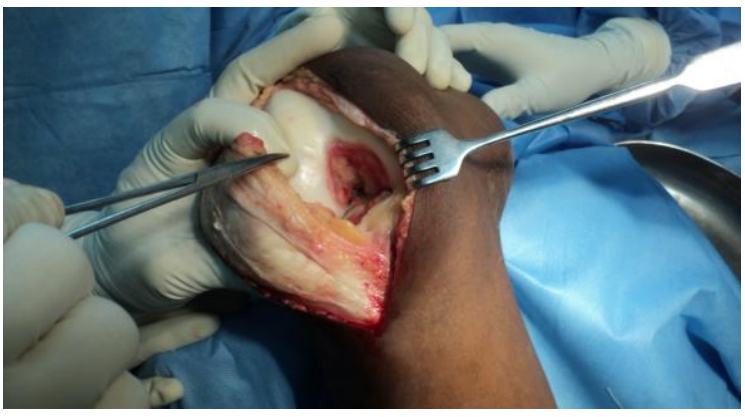

Fig 2: Post medial parapatellar arthrotomy

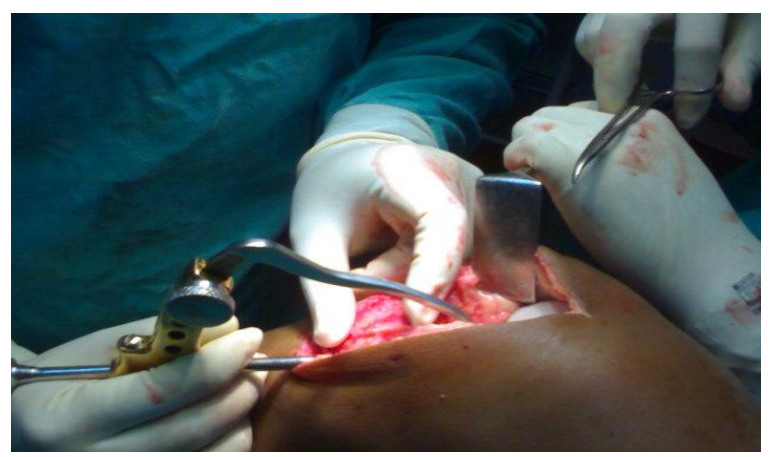

Fig 3: Tibial tunnelling

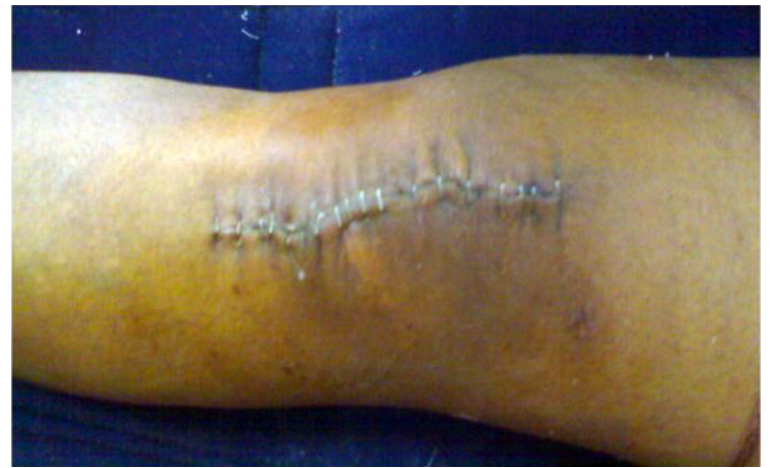

Fig 4: Tenth post op day 
Both ends were tied with vicryl to fecilitate graft passage. The bone-tendon-bone graft was placed in lactated Ringer solution with antibiotics. We Excised the femoral and tibial stump remnants of the torn anterior cruciate ligament, carefully protecting the posterior cruciate ligament. With the posterosuperior apex of the intercondylar notch representing the 12-o'clock position, pilot hole was made at the 11-o'clock position in a right knee and at the 1-o'clock position in a left knee, then drilling was done to make femoral tunnel. The exit site for the femoral tunnel was 3 to $4 \mathrm{~cm}$ proximal to the lateral femoral epicondyle. The pilot tibial tunnel was made by drilling a guide pin through the medial tibial condyle, entering the joint at the posterior half of the tibial attachment of the anterior cruciate ligament. Guide wire was passed at an approximately 30-55 degree angle with the tibia, then drilling was done.

BPTB graft passed through tibial tunnel, intercondylar notch and femoral tunnel by using suture passer. Once the graft had been properly positioned in the tunnel, we inserted an appropriate-size interference titanium screw into the femoral tunnel. Maintaining sufficient tension in graft, tibial end of the graft was fixed with appropriate size titanium interference screw. Carefull probing was done to confirm proper tension and to ensure that neither interference screw exits at the internal apertures of either tunnel and that articular fragments of bone and cartilage had not been pulled into the joint. After thoroughly lavaging the joint, wound was closed in layers.

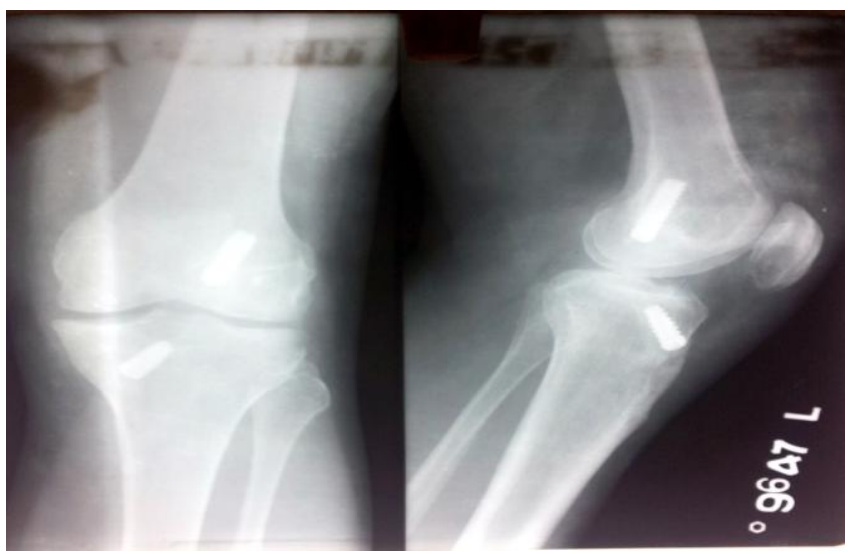

Fig 5: Post-op Radiograph
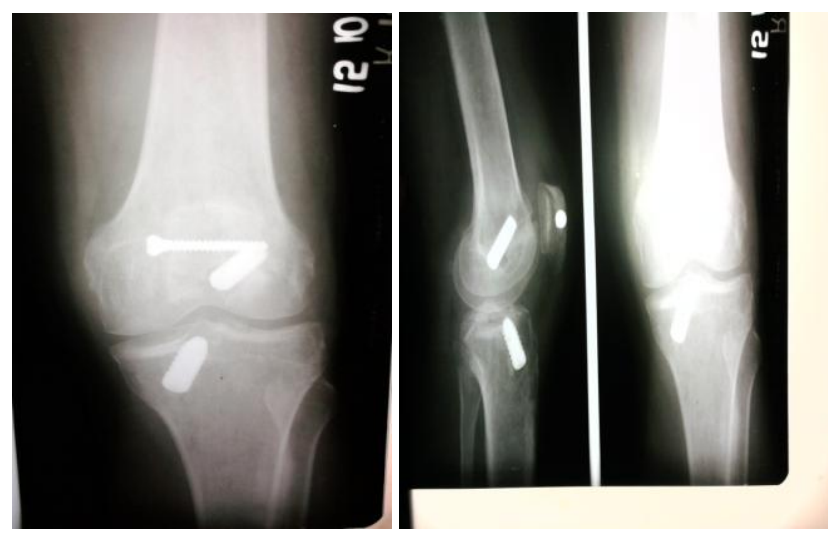

Fig 6: Iatrogenic patella fracture, fixed with screw

Second post op day wound was inspected and fresh dressing applied. Thereafter wound was inspected every third day. Stiches were removed on tenth-fourteenth post op day. Rehabilitation was done in the following manner. 0 to $2 \mathrm{wk}$ : Full knee extension \&90 deg flexion ROM exercises, SLR, partial weight bearing with crutches. 2 to $4 \mathrm{wk}$ : ROM $\rightarrow 0$ TO
$120 \mathrm{deg}$, full weight bearing, tread mill. 4 to $6 \mathrm{wk}$ : Full ROM exercises, quadriceps and hamstring strengthening. 8 to $10 \mathrm{wk}$ : Strengthening exercises continued, slow running. 12 to $14 \mathrm{wk}$ : Jogging. 16 to $18 \mathrm{wk}$ : Sport specific training, plyometric exercises. 5 to $6 \mathrm{~m}$ : Return to sport or manual work. The Lysholm And Gillquist, IKDC 2000 scores were used to analyse the functional outcome with regard to range of movement, ligament laxity, harvest site pathology ${ }^{[6]}$.

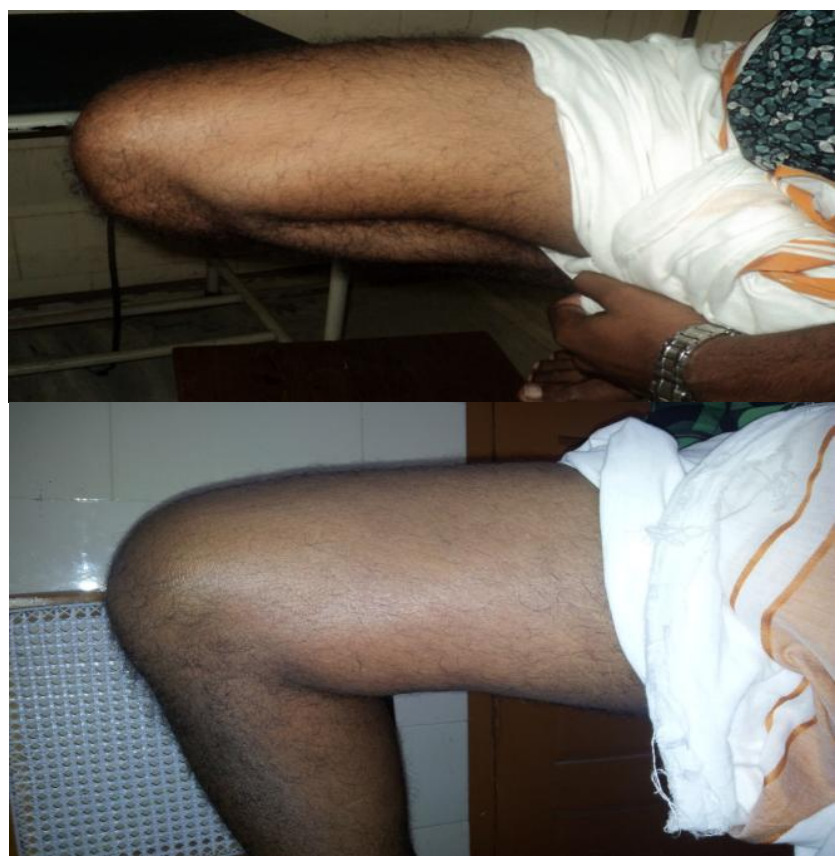

Fig 7: Knee flexion

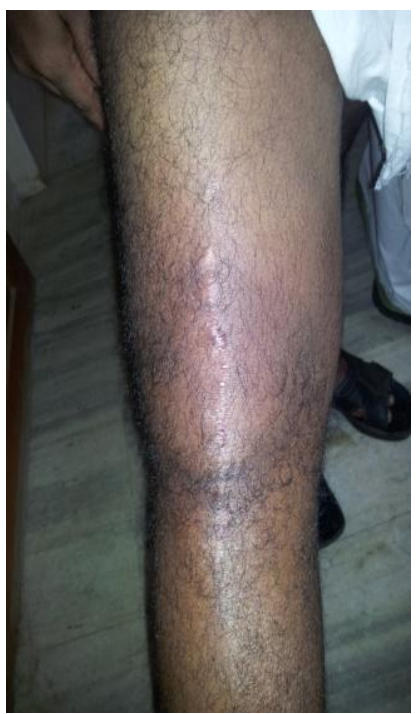

Fig 8: Knee extension

\section{Results}

Table 1: Age distribution

\begin{tabular}{|c|c|c|}
\hline Age & No of case & Percentage \\
\hline $20-25$ & 9 & 30 \\
\hline $26-30$ & 8 & 27 \\
\hline $31-35$ & 6 & 20 \\
\hline $36-40$ & 6 & 20 \\
\hline $41-45$ & 1 & 3 \\
\hline
\end{tabular}




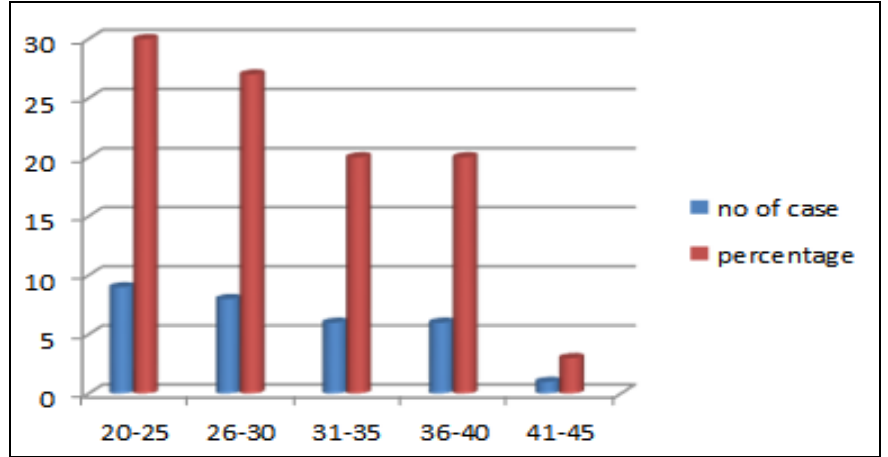

Table 2: Mode of injury

\begin{tabular}{|c|c|c|}
\hline Moi & No Of Case & Percentage \\
\hline Sports & 19 & 63 \\
\hline Fall & 11 & 37 \\
\hline Rta & 0 & 0 \\
\hline
\end{tabular}

Table 3: Side

\begin{tabular}{|c|c|c|}
\hline Side & No Of Case & Percentage \\
\hline Right & 20 & 67 \\
\hline Left & 10 & 33 \\
\hline
\end{tabular}

Table 4: Grades obtained based on Lysholm score

\begin{tabular}{|c|c|c|}
\hline Grade & No Of Case & Percentage \\
\hline Excellent & 2 & 7 \\
\hline Good-Excellent & 23 & 77 \\
\hline Fair -Good & 3 & 10 \\
\hline Fair & 1 & 3 \\
\hline Poor & 1 & 3 \\
\hline
\end{tabular}

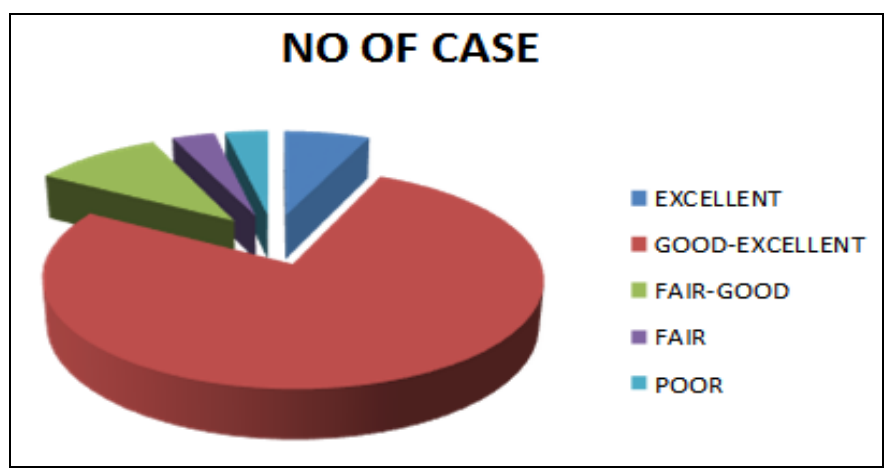

Table 5: Grades obtained based on IKDC-2000 score

\begin{tabular}{|c|c|c|}
\hline Grade & No Of Case & Percentage \\
\hline Normal & 3 & 10 \\
\hline Nearly Normal & 24 & 80 \\
\hline Abnormal & 3 & 10 \\
\hline Severely Abnormal & 0 & 0 \\
\hline
\end{tabular}

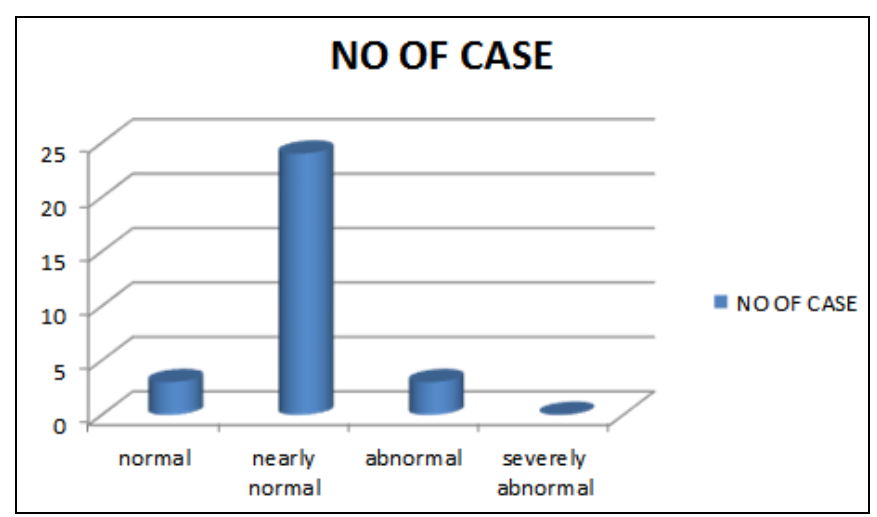

In our study of 30 patients, all were males. Right knee was affected in 20 patients, left knee was affected in remaining 10 patients. The youngest patient was $20 \mathrm{yr}$ of age, and oldest was $41 \mathrm{yr}$ of age. Many patients were in age group of 20-30yr, 12 patients were in the age group of 31-40. Only one patient was in the age group of 41-45.

Most of the patients (19) had ACL tear during recreational sports activity (football, volley ball). Eleven patients (37\%) gave the history of fall due to slippage or while walking in uneven ground. We didnot have cases due to RTA. We didnot have cases with bilateral ACL injury. Eleven cases (37\%) had medial meniscus injury, four cases $(13 \%)$ had lateral meniscus injury, for which meniscectomy was done. One patient had patella fracture while harvesting BPTB graft, exact reason was not known but could be due to technical fault. There was no anaesthetic complications, no significant immediate post-operative complications. There was no frank infection or septic arthritis in our study cases.

All cases were assessed using Lysholm \& Gillquist score and IKDC 2000 scoring system, after 12-24 month post-surgery. According to IKDC objective evaluation, knees were normal in 3 cases, nearly normal in 24 cases $(80 \%)$, abnormal in 3 cases (10\%). According to Lyman $\mathrm{J}$ et al and Russel VJ et al study, $97 \%$ of cases had normal -near normal grade. In our study $90 \%$ of cases had normal-near normal grade.

According to Lysholm scoring system, 25 cases (84\%) obtained excellent or good-excellent grade, 3 cases obtained fair-good grade, one case obtained fair grade, one case obtained poor grade. In a study by A. Klakov, A. Putz and W. Neumann, the mean lysholm score was 95 . In another study by Patel V, Anthony J Hall, the mean Lysholm score was 88.5. In our study the mean Lysholm score was 93. Among three cases which obtained abnormal grade in IKDC scoring system, one patient had graft failure due to slippage of femoral bone plug following trivial fall, one patient had persisting instability due to faulty anterior placement of femoral tunnel, one patient had significant loss of flexion $\left(20^{0}\right)$.

Eight patients had anterior knee pain,17 patients (57\%) had flexion loss (mean $7.6^{\circ}$ ), two patients had extension lag of 3$5^{0}$. Shaieb et al (2002) found flexion loss in 52\% of cases and mean loss was $3.4^{0}$. Ten patients $(34 \%)$ had kneeling pain, four patients had mild numbness over donor site. Two patients had positive Lachman and Pivot shift test. In one case, reason was graft failure as i mentioned earlier. In another case, reason could be due to anterior placement of femoral tunnel. Aune et al, Bach abd Boonos, Bartlett et al found higher incidence of anterior knee pain or kneeling pain among BPTB group. In a study by Narendra joshi, Kanniraj, Mrinal Sharma, $20 \%$ of cases had anterior knee pain, $4 \%$ had extension lag of $3-5^{0}, 8 \%$ cases had mild numbness over donor site, $4 \%$ cases had positive Lachman test, $5 \%$ cases had positive Pivot shift test.

\section{Discussion}

In our study,the age group most commonly (77\%) involved was 20-35yr. Majority of the patients(63\%) sustained ACL injury due to recreational sports activities, mainly foot ball and volley ball. Right knee $(67 \%)$ was more commonly involved than left. Associated meniscal injury was found in $50 \%$ of the patients. One patient had patella fracture per operatively, this can be avoided by using electric saw and being more cautious while harvesting bone plug from Patella. According to IKDC 2000 scoring system, 90\% of patients had normal or near normal knee, and $10 \%$ of the patients had 
abnormal knee.

According to Lysholm and Gillquist scoring system, $83 \%$ of the patients had excellent or good-excellent grade, $3 \%$ of the patients had poor grade, others $(14 \%)$ had intermediate grade (fair-good, fair). We obtained the mean lysholm score as 93. In this study, $26 \%$ of the cases had anterior knee pain, $13 \%$ of the patients had mild numbness over graft donor site, $57 \%$ of the patients had flexion loss, mean loss was 7.6 . Only two patients had extension lag of $3-5^{0}$.

Results obtained in our study are comparable to the outcome following arthroscopic ACL reconstruction using Autologus BPTB graft. According to various literatures, limited surgical scar, limited duration of post op pain are the only advantage of arthroscopic reconstruction, but the average time taken for the surgery is more when compared to open reconstruction. It is technically demanding, needs costly instruments, long learning curve. So still open reconstruction has a role especially in Government hospitals, Sub urban area in developing countries like India. Regarding stability and return to pre-injury activity, BPTB graft is superior than hamstring graft because the union is between bone and bone in BPTB whereas it is tendon to bone healing in case of hamstring gfaft [12-15]

Extension lag or loss of flexion encountered in this study was mainly due to poor compliance of patients in Rehabilitation programme, since physiotherapy plays vital role in functional outcome. According to our study and many literatures, anterior knee pain or kneeling pain is high when we use BPTB graft. So it is better to consider hamstring graft for those patients who kneel frequently (Carpet layers, Tilers, Muslims) and who need good quadriceps power (Basket-ball players, Tennis players); for all others BPTB is the best choice.

\section{References}

1. Torry MR, Decker MJ, Jockel JR. Comparison of tibial rotation strength in patients' status after anterior cruciate ligament reconstruction with hamstring versus patellar tendon autografts. Clin J Sport Med. 2004; 14:325-31.

2. Corry IS, Webb JM, Clingeleffer AJ. Arthroscopic reconstruction of the anterior cruciateligament. A comparison of patellar tendon autograft and four-strand hamstring tendon autograft. Am J Sports Med 1999; 27:444-54.

3. Mir SM, Hadian MR, Talebian S. Functional assessment of knee joint position sense following anterior cruciate ligament reconstruction. Br J Sports Med. 2008; 42:300303.

4. Insalata LJC, Klatt $\mathrm{B}, \mathrm{Fu}$ FH. Tunnel expansion following anterior cruciate ligament reconstruction: acomparison of hamstring and patellar tendonautografts. Knee Surg Sports Traumatol Arthrosc. 1997; 5:234-8.

5. Biomechanics and anterior cruciate ligament reconstruction Savio L-Y Woo, Changfu Wu, Ozgur Dede, Fabio Vercillo and Sabrin Noorani.

6. Lephart SM, Kocher MS, Harner CD. Quadriceps strength and functional capacity afteranterior cruciate ligament reconstruction. Patellartendon autograft versus allograft. Am J Sports Med. 1993; 21:738-43.

7. Rupp S, Muller B, Seil R. Knee laxity after AC Lreconstruction with a BPTB graft. Knee Surg Sports Traumatol Arthrosc. 2001; 9:72-6.

8. James R. Carmichael and Mervyn J Cross: Why bonepatella tendon-bonegrafts should still beconsidered the gold standardfor anterior cruciate ligamentreconstruction.
Br J Sports Med. 2009 43:323-325 published online March 8, 2009.

9. Bradley JP, Klimkiewicz JJ, Rytel MJ. Anteriorcruciate ligament injuries in the National Football League: epidemiology and current treatment trendsamong team physicians. Arthroscopy. 2002; 18:502-9.

10. Grays anatomy-Anatomical basis of clinical practice, Fortieth edition.

11. Clinicalanatomybysystems, Richard S. Snell.

12. Li S, Chen Y, Lin Z, Cui W, Zhao J, Su W. A systematic review of randomized controlled clinical trials comparing hamstring autografts versus bone-patellar tendon-bone autografts for the reconstruction of the anterior cruciate ligament..

13. Xie X, Liu X, Chen Z, Yu Y, Peng S, Li Q. A metaanalysis of bone-patellar tendon-bone autograft versus four-strand hamstring tendon autograft for anterior cruciate ligament reconstruction.

14. Daniel A Shaerf, Philip S Pastides, Khaled M Sarraf, Charles A Willis-Owen. Anterior cruciate ligament reconstruction best practice: A review of graft choice.

15. Romanini E, Angelo DF, De Masi S, Adriani E, Magaletti M, Lacorte $\mathrm{E}$ et al. Graft selection in arthroscopic anterior cruciate ligament reconstruction. J Orthop Traumatol. 2010; 11:211-219. 